\title{
Investigation of crack-tip plasticity in high volume fraction particulate metal matrix composites
}

\author{
A. Miserez, A. Rossoll, A. Mortensen * \\ Laboratory for Mechanical Metallurgy, Institute of Materials, Swiss Federal Institute of Technology in \\ Lausanne (EPFL), Lausanne 1015, Switzerland
}

Received 14 April 2003; received in revised form 12 December 2003; accepted 13 January 2004

\begin{abstract}
Crack-tip strain fields in high volume fraction ceramic particle reinforced metal matrix composites are assessed using photoelastic measurements. It is shown that the size of the significant crack-tip plastic zones that form in these materials depends on the type and diameter of the reinforcement and on the matrix material. This plastic zone size correlates well with the macroscopic toughness values assessed through $J$-integral testing. The composites are thus "metallic" in the sense that their toughness is mostly composed of plastic energy dissipation around the crack tip. Plastic deformation also induces marked constraint effects that influence the shape of the surface strain fields. It is shown that finite element analysis must be three-dimensional to describe these strain fields, as two-dimensional plane-stress analysis fails to reproduce the experimental data.

(c) 2004 Elsevier Ltd. All rights reserved.
\end{abstract}

Keywords: Metal matrix composites (MMCs); $J$-integral testing; Photoelasticity; Crack-tip plasticity; Three-dimensional (3-D) effects

\section{Introduction}

Particulate reinforced metal matrix composites (PRMMCs) are classical examples of ductile/brittle twophase materials, in which a ductile matrix is combined with rigid and brittle ceramic particles, generally with a goal of producing a lightweight material that is stiff and strong with attractive physical properties such as a low coefficient of thermal expansion or a high thermal conductivity. The major drawbacks of these materials are associated with their relatively poor fracture properties, i.e. they are often brittle, especially at higher volume fraction of reinforcement [1-4].

There exists, however, experimental evidence that such composites are "metallic" in terms of their fracture behaviour, in that the major part of the fracture energy is spent in forming and propagating a plastic crack-tip zone. This was shown by Davidson [5-7] using a stereo-imaging technique to visualise crack-tip strain fields, and was later qualitatively corroborated by Flom and Arsenault [8]. Other fracture

\footnotetext{
${ }^{*}$ Corresponding author. Fax: +41-21-693-4664.

E-mail address: andreas.mortensen@epfl.ch (A. Mortensen).
} 
data confirm that a significant plastic zone is formed: $K_{\text {Ic }}$ values exceeding $20 \mathrm{MPa} \mathrm{m}^{1 / 2}$ have indeed been reported in various studies or reviews [3,9-15]. According to elementary fracture mechanics, such toughness values must be associated with significant crack-tip plastic deformation given the moderate yield stress of these materials.

Davidson's observations of crack-tip plastic zones in PRMMCs concentrated on near crack-tip fields, about $100 \mu \mathrm{m}$ in front of the crack tip [13]. To the authors' knowledge, there have not been other attempts to visualise the crack-tip plastic zone on a larger scale in particle reinforced metals. Also, in work to date the volume fraction $\left(V_{\mathrm{f}}\right)$ of reinforcement was typically in the range $15-20 \%$. We present here results from a direct examination of crack-tip plastic zones in higher fraction ceramic composites, for which $V_{\mathrm{f}}$ is comprised between $45 \%$ and $60 \%$. Even though they are half-ceramic, these composites can display a relatively high fracture toughness, coupled with significant $R$-curve behaviour [16,17]. These results motivated the present study, which aims to show with clarity the "metallic" fracture behaviour of these half-metal/halfceramic materials by direct observation of crack-tip plastic zone dimensions. To this end, we use reflection photoelasticity through a polymeric coating applied on the surface of the composites to track the evolution of the crack-tip plastic zone along the surface of $J$-integral fracture testing specimens.

In order to obtain the total elastic-plastic strain field (and, in turn, the boundary with the crack-tip plastic zone) in elastoplastic materials other techniques are generally used, such as stereoimaging [18], Moiré interferometry [19,20], or laser-speckle interferometry [21-23]. By contrast, because photoelasticity provides only the elastic strain fields in the birefringent coating, it is mainly used to determine experimentally stress intensity factors for complex loading modes in components where the fields are predominantly linear elastic [24-27]. Because constraint effects that arise in elastic-plastic materials are then weak, such experimental data agree reasonably well with theoretical plane-stress solutions. In the presence of significant plastic deformation, in reflection photoelasticity the coating (which remains elastic) simply acts as a witness to the in-plane strains along the surface of the test specimen. Hence, by selecting the appropriate coating with respect to the expected strain levels in the test material, one can use reflection photoelasticity to observe and quantify the total elastic-plastic field in underlying elastic-plastic materials; the present experiments are based on this idea.

The observed strain fields are compared for the same value of $J$ with (i) the plane-stress HRR (Hutchinson-Rice-Rosenfield) solution, (ii) two-dimensional (2-D) finite element (FE) analysis in plane stress, and (iii) fully three-dimensional (3-D) FE analysis. Early attempts made to correlate the $J$-integral and surface strain measurements with the HRR field in various unreinforced Al alloys have been made by Chan [18] or Dadkah and Kobayashi [19]. Such comparisons led to the conclusion that neither the plane stress nor the plane strain HRR fields adequately describe the observed fields on the specimen surfaces. The unsatisfactory description through the plane-stress HRR field was attributed to crack extension in the latter study, while three-dimensional effects were invoked in the former. Proof of such a three-dimensional constraint effect by a fully experimental/computational comparison was not conducted at that time, possibly because computational procedures to perform 3-D analyses of cracked specimens were not as well established and as rapid as nowadays. Indeed, it has been increasingly understood in the past decade that surface measurements are affected by 3-D effects [28-30], and that caution must be exercised in analysis of experimental data. For instance, it has been shown that plane-stress approximations are not sufficient to fit experimental measures such as the crack-tip opening angle (CTOA) or the crack-tip opening displacement (CTOD) (which are the surface measurements of crack-tip loading that are the most commonly performed), whereas 3-D analyses yield much better agreement [20,30-32].

We therefore compare here the global surface strain fields of compact tension (CT) specimens with fully three-dimensional elastic-plastic FE computations. To the best of our knowledge, such comparisons between elastic-plastic strain fields observed by experiment and numerically computed have rarely been performed. Three-dimensional constraint effects have, rather, been assessed by correlating numerical computations with other measurements, which are more directly accessible such as the CTOA, the CTOD or 
load-displacement curves [20,31-36]. A second goal of this investigation is therefore to evaluate the significance of three-dimensional "constraint" effects with these half-metal/half-ceramic composite materials.

\section{Experimental procedures}

\subsection{Materials processing and designation}

The composites were processed by gas-driven pressure infiltration. In summary, preforms of loose ceramic particles are prepared by tapping ceramic powders to maximum density, and then infiltrated by the liquid matrix material in a high-pressure chamber. Details of the processing method can be found elsewhere [37-41]. Advantages of the method include the possibility to process "model" composites in which the particles are uniformly dispersed within a metallurgically simple matrix, and which are free of defects introduced in the processing stage (e.g., oxide inclusions, uncontrolled reaction phases at the interfaces, or non-uniform distribution of the particles). Different composite microstructures are obtained by varying one of the following initial parameters: (i) the particle chemistry and/or shape, (ii) the average reinforcement size, and (iii) the matrix alloy.

Three different types of reinforcement are used: (i) angular-shaped $\alpha-\mathrm{Al}_{2} \mathrm{O}_{3}$ particles $(99.5 \%$ purity) with an average size of $30 \mu \mathrm{m}$; (ii) high purity $(99.99 \%)$ polygonal-shaped $\alpha-\mathrm{Al}_{2} \mathrm{O}_{3}$ particles with an average size of 15 or $5 \mu \mathrm{m}$; and (iii) angular $\mathrm{B}_{4} \mathrm{C}$ particles with an average size of 60 or $10 \mu \mathrm{m}$. One must note that not only the reinforcement shape or chemistry differ but also their quality. Angular $\mathrm{Al}_{2} \mathrm{O}_{3}$ powders contain a certain number of cracks that are visible on the surface under the scanning electron microscope (SEM), $\mathrm{B}_{4} \mathrm{C}$ powders have elliptic pores visible at their surface, whereas no defects are found along the surface of the polygonal $\mathrm{Al}_{2} \mathrm{O}_{3}$ powders [42]. Typical microstructures for the composites of this work are given in Fig. 1.

Matrices employed are high purity $\mathrm{Al}(99.99 \%)$ or $\mathrm{Al}-\mathrm{Cu} 2 \%$ alloy. For $\mathrm{Al}-\mathrm{Cu} 2 \%$ alloy matrix composites, a solution heat-treatment was performed prior to fracture testing in order to dissolve intermetallic second-phases formed during solidification at ceramic/metal interfaces, which were found to affect the fracture properties of the composites [17]. Fracture tests were conducted on solutionised (T4) specimens.

A summary of the different composites presented in this study, giving the ceramic type, size, volume fraction of reinforcement, and matrix alloy, is given in Table 1. For clarity, the composites will be designated hereafter according to the last column in this table.

\section{2. $J-R$ curve testing}

Despite the high volume fraction of ceramic particles, the pure Al matrix composites are too ductile for linear elastic fracture mechanics (LEFM) testing with reasonably sized specimens (i.e., specimens smaller than a casting billet). Hence, their fracture characteristics were tested by the $J$-integral method, using the single specimen technique according to ASTM E-1737 [43] for the generation of $J-R$ curves. Al-Cu matrix composites were tested using the same method. Compact tension (CT) specimens with a thickness of $13 \mathrm{~mm}$ (the other dimensions corresponding to $10 \mathrm{~mm}$ thick standard CT specimens) were cut by electro-discharge machining (EDM) and carefully pre-cracked by fatigue loading on a $25 \mathrm{kN}$ servohydraulic testing machine (Instron model 8872, Canton, MA, USA). Due to the difficulty in pre-cracking such materials a specific procedure had to be developed, which consists of the following steps:

(i) A series of one to a few thousand load cycles is conducted at controlled load amplitude, with a load ratio $P_{\max } / P_{\min }$ of 10 . This corresponds to a maximum stress intensity factor $K_{\max }$ in the range of 6-8 $\mathrm{MPa} \mathrm{m}{ }^{1 / 2}$ for most of our materials. The A2C-A15p composite necessitates a significantly larger $K_{\max }$ (around $13 \mathrm{MPa} \mathrm{m}^{1 / 2}$ ) to initiate and propagate the fatigue pre-crack. 

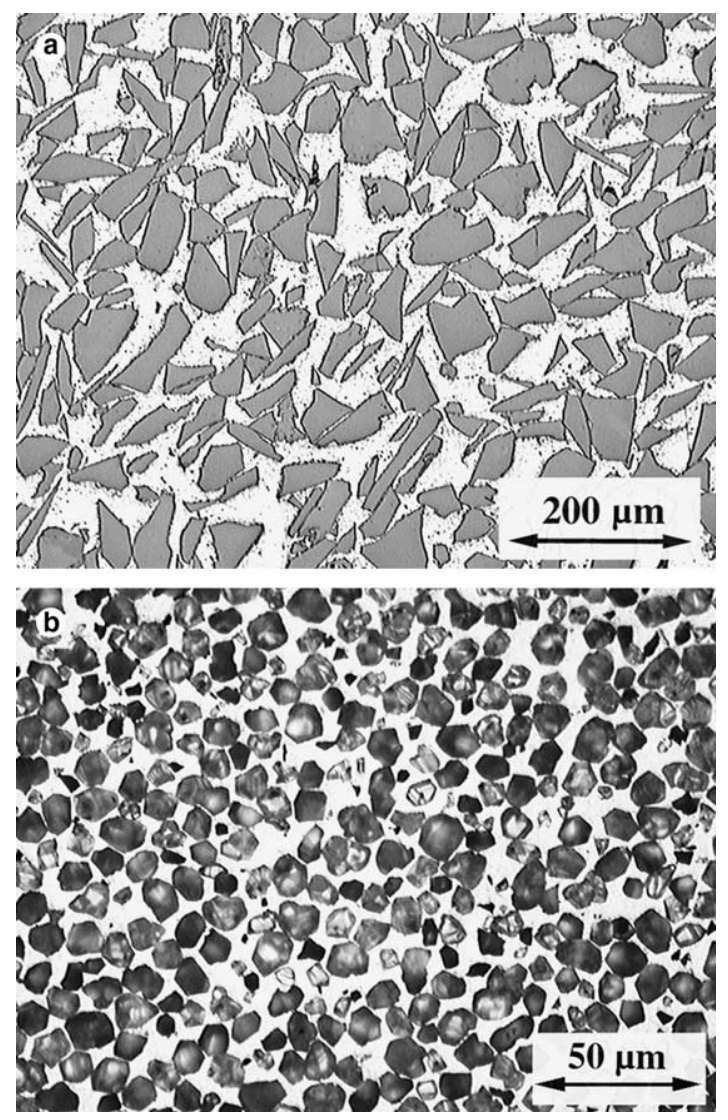

Fig. 1. Optical micrographs illustrating typical microstructures of the composites: (a) $60 \mu \mathrm{m}$ B4C reinforced composite; (b) $15 \mu \mathrm{m}$ polygonal $\mathrm{Al}_{2} \mathrm{O}_{3}$ reinforced composite. The volume fraction of ceramic particles (in dark) ranges between $50 \%$ and $60 \%$.

Table 1

Summary of composites presented in this study $\left(V_{\mathrm{f}}\right.$ : volume fraction of reinforcement)

\begin{tabular}{lllll}
\hline Matrix & Reinforcement type & Average reinf. size $(\mu \mathrm{m})^{\mathrm{a}}$ & $V_{\mathrm{f}}(-)$ & Composite designation \\
\hline Pure $\mathrm{Al}(99.99 \%)$ & $\mathrm{Al}_{2} \mathrm{O}_{3}$ angular & 35 & 0.45 & $\mathrm{~A}-\mathrm{A} 35 \mathrm{a}$ \\
Pure $\mathrm{Al}(99.99 \%)$ & $\mathrm{Al}_{2} \mathrm{O}_{3}$ polygonal & 15 & 0.58 & $\mathrm{~A}-\mathrm{A} 15 \mathrm{p}$ \\
Pure $\mathrm{Al}(99.99 \%)$ & & 5 & 0.56 & $\mathrm{~A}-\mathrm{A} 5 \mathrm{p}$ \\
Pure $\mathrm{Al}(99.99 \%)$ & $\mathrm{B}_{4} \mathrm{C}$ angular & 60 & 0.54 & $\mathrm{~A}-\mathrm{B} 60$ \\
Pure $\mathrm{Al}(99.99 \%)$ & & 10 & 0.52 & $\mathrm{~A}-\mathrm{B} 10$ \\
$\mathrm{Al}-\mathrm{Cu} 2 \%$ & $\mathrm{Al}_{2} \mathrm{O}_{3}$ angular & 60 & 0.52 & $\mathrm{~A} 2 \mathrm{C}-\mathrm{A} 60 \mathrm{a}$ \\
$\mathrm{Al}-\mathrm{Cu} \%$ & $\mathrm{Al}_{2} \mathrm{O}_{3}$ polygonal & 15 & 0.58 & $\mathrm{~A} 2 \mathrm{C}-\mathrm{A} 15 \mathrm{p}$ \\
\hline
\end{tabular}

${ }^{a}$ Medium value of the size distribution, as measured by centrifugal sedimentation.

(ii) The specimen is removed from the machine and crack propagation is revealed on the surface, using a non-destructive fluorescent penetrant dye and optical microscopic observation under ultraviolet light. Alternatively crack propagation is determined by measuring the specimen elastic compliance. 
(iii) The specimen is reinserted into the machine and a new series of cycles is conducted at a load adapted to take into account the degree of crack advance from the precedent series of cycles.

(iv) These steps are repeated until the crack length satisfies the requirements of ASTM E-1737.

It was also verified that the maximum load and stress intensity factor during pre-cracking satisfied ASTM E-1737 conditions.

$J$-integral fracture testing was conducted on a $100 \mathrm{kN}$ screw-driven universal testing machine (Zwick, Ulm, Germany). A clip-on gauge extensometer (model 632.03F-30, MTS, Minneapolis, USA) was used to monitor the load-line crack mouth opening displacement (CMOD). The tests were conducted under crosshead control at a velocity of $50 \mu \mathrm{m} / \mathrm{min}$. Initial unloading/reloading cycles (at least three) were carried out in the elastic regime to estimate the initial crack length from the specimen compliance. Subsequent unloading/reloading cycles were made at regular load increments of 0.1 and $0.2 \mathrm{kN}$. The minimum load during a cycle was set between $15 \%$ and $20 \%$ of the maximum load at unloading. The cycles were carried out at smaller intervals close to maximum load, which allowed the acquisition of a higher amount of data in the critical region of the $J-R$ curves.

\subsection{Observation of crack-tip fields by photoelasticity}

Reflective photoelasticity was employed as a means to quantify the crack-tip strain fields on the surface of the specimens. Observations were carried out during $J$-integral testing, using a dark-field reflection polariscope (Measurements Group model 031, Inc., Rayleigh, NC, USA). The view of the crack-tip region was enlarged using a telemicroscope (Measurements Group, Model 13), while acquisition of the strain fields was made with a $35 \mathrm{~mm}$ camera.

Two photoelastic coatings of respectively 0.51 and $1.1 \mathrm{~mm}$ thickness were used, depending on the strain resolution needed to characterise the composites. The coatings were cut to match the geometry of the region situated in front of the crack tip and then bonded on the specimen surface with a two-component adhesive ("PC-6" resin and "PCH-6" hardener, Measurements Group). Further details regarding the photoelastic set-up, specimen preparation, and bonding procedures can be found in the instruction manuals of the supplier [44]. For the majority of observations, the middle of the coating film was cut as indicated in Fig. 2 in order to avoid direct loading of the photoelastic film across the open crack, as this results in artefacts in the photoelastic pattern. Some observations were also conducted without this final cut: these were more precise in revealing the position of the crack tip and the strains on the crack plane; however, their drawback is that behind the crack tip, the measured strain level is influenced by stretching of the film across the open crack.

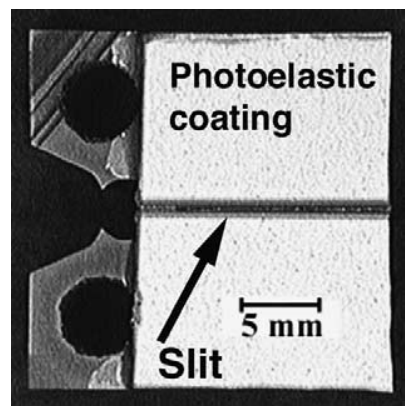

Fig. 2. Compact tension (CT) specimen with bonded reflective photoelastic coating. A slit is machined across the middle of the coating after bonding to avoid direct loading of the coating through the open crack. 
Observations of the photoelastic patterns were conducted in the full-field interpretation mode. The images of the photoelastic pattern were taken during $J$-integral fracture testing. In order to correlate the crack-tip strain fields with the value of the $J$-integral, the pictures were taken at the beginning of the unloading/reloading cycles used for determining the current crack length. The low luminosity of the photoelastic fields necessitates long exposure times, which is why the test machine was stopped during exposure. Identification of fringe orders and corresponding shear strains was made using the isochromatic fringe characteristics given by the supplier, and the fringe value of the coatings.

\section{Computational procedures}

\subsection{Constitutive behaviour}

The uniaxial stress-strain flow curves of the composites for which crack-tip strain fields were computed have been published elsewhere $[17,42,45]$. These curves were then fitted with the Ramberg-Osgood equation:

$$
\frac{\varepsilon}{\varepsilon_{0}}=\frac{\sigma}{\sigma_{0}}+\alpha\left(\frac{\sigma}{\sigma_{0}}\right)^{n}
$$

where $\alpha=3 / 7, n$ is the strain hardening coefficient, and $\varepsilon_{0}$ and $\sigma_{0}$ are the yield strain and stress, respectively. Because damage accumulation, which renders the material anisotropic, occurs from the onset of plastic deformation in these materials, "effective" tensile curves corrected for damage were used. Hence damage is not taken into account in computing the crack-tip plastic strains; however, this has essentially no influence on the present results given the rapid decay of strain with distance from the crack tip. Effective curves were generated for pure $\mathrm{Al}$ matrix composites in $[42,46]$ on the basis of the measured change in the elastic modulus. The same method was used for the $\mathrm{Al}-\mathrm{Cu} 2 \%$ matrix composites. The Ramberg-Osgood relation can be made to fit the effective tensile data of the composites very well. Fitting parameters of the composites for which photoelastic observations were compared with analytical and FE computations are given in Table 2.

We note that, since the parameters of the HRR solution are available in tabulated form for integer values of the strain hardening parameter $N(=1 / n)$ only, such integer values were imposed for fitting the parameters of the Ramberg-Osgood equation that were used for the HRR solution. No such limitation restricted the choice of parameters used in finite element analysis, such that $\varepsilon_{0}$ was then defined as $\sigma_{0} / E$ where $E$ is the actual Young's modulus (the Ramberg-Osgood law is hence in the form: $\varepsilon=\sigma / E+$ $\left.\alpha\left(\sigma_{0} / E\right)\left(\sigma / \sigma_{0}\right)^{n}\right)$. Both descriptions yield very similar fits for the "effective" non-damaged composite tensile curves.

Table 2

Ramberg-Osgood parameters obtained by fitting the composite flow stress curves, used for HRR or FE analysis

\begin{tabular}{lllll}
\hline Composite & $N(=1 / n)$ & $\sigma_{0}(\mathrm{MPa})$ & $\varepsilon_{0}(-)$ & $E(\mathrm{GPa})$ \\
\hline A-A15 $^{\mathrm{a}}$ & 4 & 64 & 0.0029 & 175 \\
A-A15 $\mathrm{p}^{\mathrm{b}}$ & 4.1 & 71 & & \\
A2CA-A15 $\mathrm{p}^{\mathrm{a}}$ & 6 & 203 & 0.00148 & 175 \\
A2CA-A15 $\mathrm{p}^{\mathrm{b}}$ & 5.3 & 177 & & 175 \\
\hline
\end{tabular}

${ }^{\mathrm{a}}$ Fit used for HRR analysis.

${ }^{\mathrm{b}}$ Fit used for FE analysis. 


\subsection{HRR fields}

Since the strain fields were observed on the specimen surface, the plane-stress solution of the HRR field [47,48] was used. The HRR field equations were programmed using Mathcad ${ }^{\mathrm{TM}}$ (Mathsoft Inc., USA), by computing the components of the deformation fields in polar coordinates according to the form given in [49] (in which the numerical factors of the HRR field are exhaustively listed). At each point, the principal values of the surface strain tensor $\left(\varepsilon_{1}, \varepsilon_{2}\right)$ were computed, from which the principal shear strain $\left(\varepsilon_{1}-\varepsilon_{2}\right)$ was derived (this corresponds to the strain component observed by photoelasticity). The crack-tip strain field $\left(\varepsilon_{1}-\varepsilon_{2}\right)$ was plotted at values of $J$ corresponding to the instant of photoelastic observations.

\subsection{FE computed fields}

The finite element simulations were carried out using the commercial finite element code ABAQUS/ Standard, version 5.8 [50]. User-routines were employed for the material constitutive equations and for the computation of the principal in-plane shear component $\varepsilon_{1}-\varepsilon_{2}$. Due to symmetry, it is sufficient to model a quarter of the three-dimensional CT specimens. A total of 32,800 brick elements with linear interpolation and reduced integration were used, comprising 20 layers of elements in the thickness direction. A decreasing layer thickness was used from the centre plane towards the surface of the specimen, in order to resolve the increasingly steeper gradients. The out-of-plane thickness of elements is $50 \mu \mathrm{m}$ for the element layer beneath the surface, and $0.75 \mathrm{~mm}$ in the specimen mid-plane.

A decreasing size of elements was used in the crack-tip region. The crack tip was modelled as straight (i.e. without crack tunnelling) and initially blunted, with a radius of $1.5 \mu \mathrm{m}$. The tangential distance of nodes at the crack tip is initially a fraction of a micron, whereas the "radial" size of the first range of elements at the crack tip is roughly $2 \mu \mathrm{m}$. In the far field, the maximum in-plane dimension of elements reaches about $0.75 \mathrm{~mm}$. The overall view of the 3-D meshes, as well as a close-up view of the crack-tip region mesh, are shown in Fig. 3. A similar mesh was used for the plane-stress model, with 1577 quadrangular linear elements with reduced integration.

The computations were carried out in a large-strain framework, using $J_{2}$ flow theory. The $J$-integral was computed along contours, and averaged over the thickness (3-D model). A large contour was necessary in order to achieve consistent values of the $J$-integral. The reason for this seemingly inconsistent behaviour (the $J$-integral is theoretically contour-independent) is that extensive plastic deformation occurs in the specimen (there is no yield point in the material), and plasticity induces a deviation of the local load path

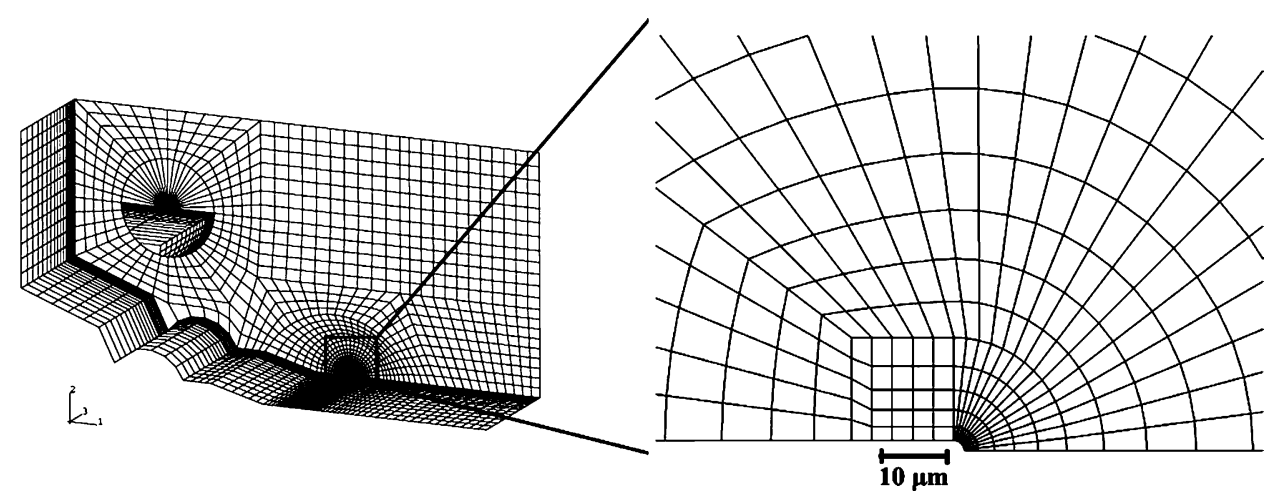

Fig. 3. Overall 3-D FEM mesh of the CT specimen and detail of the crack-tip region. 
from radial loading, which is implicitly required when approximating plasticity with non-linear elasticity (see also the comprehensive discussion by Brocks and Scheider [51]).

The crack length $a_{0}$ was imposed to match the initial crack length of the particular samples used for $J-R$ curve measurements and photoelastic observations. Crack advance not being modelled in the computations, it was verified whether this would influence the crack-tip strain fields. Thus a second set of computations was carried out for a crack length $a_{1}$ matching the crack length at the instant of photoelastic observations.

\section{Results}

\subsection{Fracture characteristics: $J-R$ curves}

Despite the presence of more than 50 vol.\% of ceramic reinforcement, the present composites exhibit significant $R$-curve behaviour. Their $R$-curve is found to vary with (i) the particle type, (ii) the particle size, and (iii) the matrix alloy. Results that are relevant for the photoelastic observations can be summarised as follows.

\subsubsection{Pure Al matrix composites}

For pure Al matrix composites the $J-R$ curves are characterised by three distinct domains, as schematically depicted in Fig. 4:

(i) A steep initial part, attributed in unreinforced metallic alloys to crack-tip blunting [52]. In the present composites, some crack extension occurs in this domain due to internal damage build-up near the crack tip at relatively low strain. This steeper part always ends in the region of qualified data according to ASTM E-1737.

(ii) A second region of lower slope that starts close to, or at, maximum load. This region clearly corresponds to macroscopic crack propagation, as witnessed by a far more rapid increase in compliance, denoting a sudden increase in the crack propagation rate. For the finer particle size $(5 \mu \mathrm{m})$, the crack often propagates in an unstable manner in this second portion of the $J-R$ curve (generally soon after the peak load).

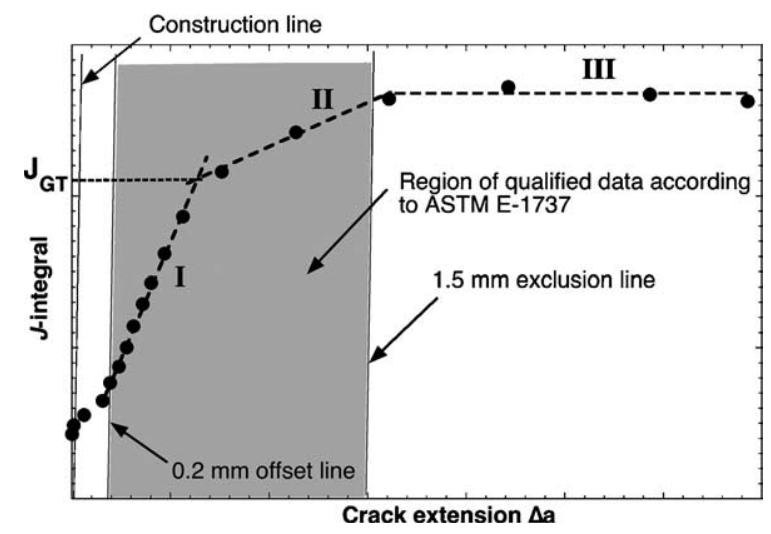

Fig. 4. Typical $J-R$ curves of the composites, showing the three distinct domains. The initiation of macroscopic crack propagation occurs at the transition between regions I and II; unstable fracture sometimes occurs in region II. 
(iii) When fully stable crack propagation occurs, a plateau value is attained, in a region well beyond the validity domain of $J$ controlled fracture.

The critical fracture parameter deduced from the $J-R$ curves is taken here as the $J$-value at the slope change of the curve, namely at the transition between the first and the second regions, as this clearly corresponds to the initiation of macroscopic crack propagation and is well within the region of $J$-controlled crack growth as defined in [53,54]. To compute this parameter, two regression lines were drawn for each part of the curves and the value called " $J_{\mathrm{GT}}$ " was defined at the intersection of the regression lines (Fig. 4).

There is a marked particle size effect in these composites, as presented in Fig. 5a for polygonal $\mathrm{Al}_{2} \mathrm{O}_{3}$ reinforced composites: the larger the average reinforcement size, the higher the fracture energy. For the smaller $(5 \mu \mathrm{m})$ particle size composites, the $R$-curve is much less marked: no specimen exhibited stable crack growth after attaining the peak load. The $J_{\mathrm{GT}}$ values at the onset of ductile tearing and the corresponding equivalent critical stress intensity factors $\left(K_{\text {eq-GT }}\right)$ are given in Table 3 . Keeping in mind the presence of 50 vol.\% brittle ceramic in these materials, the measured $K_{\text {eq-GT }}$ values exceeding $30 \mathrm{MPa} \mathrm{m} \mathrm{m}^{1 / 2}$ are very high. Tensile characteristics reproduced from $[42,45]$ are also included in the table (yield stress, $\sigma_{\mathrm{ys}}$, ultimate
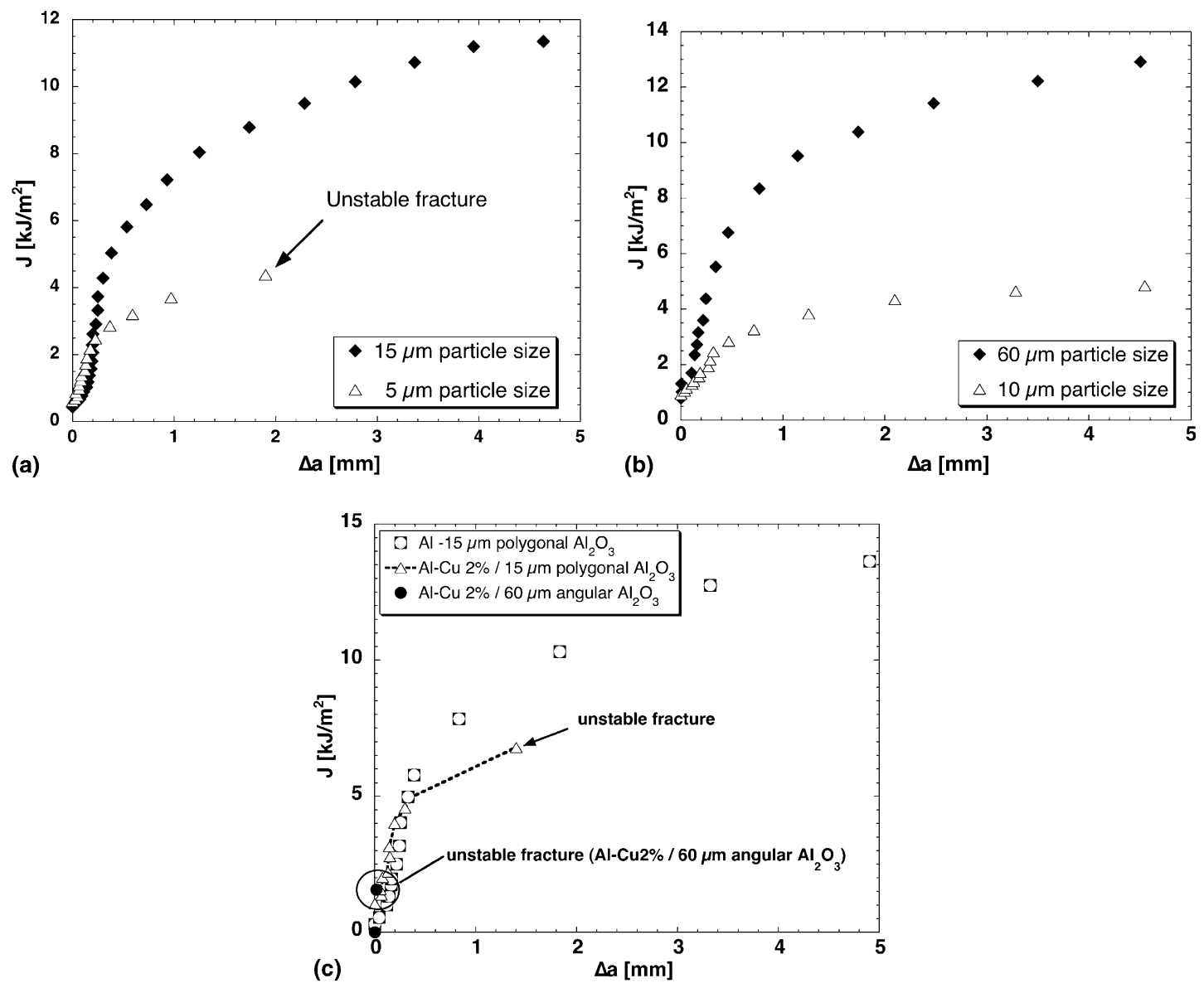

Fig. 5. $J-R$ curves of the composites. (a) Al/polygonal $\mathrm{Al}_{2} \mathrm{O}_{3}$ composites; (b) $\mathrm{Al} / \mathrm{B}_{4} \mathrm{C}$ composites; (c) $\mathrm{Al}-\mathrm{Cu} 2 \% / \mathrm{Al}_{2} \mathrm{O}_{3}$ composites: influence of matrix alloying. 
Table 3

Fracture toughness (defined at the onset of ductile tearing or at unstable fracture in the absence of ductile tearing), and tensile characteristics of the composites

\begin{tabular}{llllrll}
\hline Composite designation & $J_{\mathrm{GT}}\left(\mathrm{kJ} / \mathrm{m}^{2}\right)$ & $K_{\text {eq-GT }}\left(\mathrm{MPa} \mathrm{m}^{1 / 2}\right)$ & $E(\mathrm{GPa})$ & $\sigma_{0.2}(\mathrm{MPa})$ & $\sigma_{\mathrm{UTS}}(\mathrm{MPa})$ & $\varepsilon_{\mathrm{f}}(\%)$ \\
\hline A-A35a & 4.4 & 25.8 & 141 & 80 & 125 & 3.2 \\
A-A15p & 5.4 & 32.5 & 175 & 120 & 230 & 4.5 \\
A-A5p & 2.6 & 22.2 & 176 & 158 & 190 & 0.6 \\
A-B60 & 7.1 & 35.9 & 169 & 91 & 132 & 2.6 \\
A-B10 & 3.2 & 23.5 & 161 & 173 & 273 & 2.4 \\
A2C-A60a & $1.6^{\mathrm{a}}$ & 16.5 & 144 & 97 & 235 & 0.17 \\
A2C-A15p & 4.3 & 28.4 & 175 & 235 & 345 & 2.2 \\
\hline
\end{tabular}

${ }^{\mathrm{a}}$ Fully brittle behaviour.

tensile strength, UTS, and strain to failure, $\left.\varepsilon_{\mathrm{f}}\right)$. This particle size effect is confirmed for the $\mathrm{Al}-\mathrm{B}_{4} \mathrm{C}$ composites (Fig. 5b and Table 3).

The resistance curves are also markedly dependent on the particle type and shape. For a given particle size it is found that polygonal $\mathrm{Al}_{2} \mathrm{O}_{3}$ composites are the toughest, followed by the $\mathrm{B}_{4} \mathrm{C}$ composites, while the angular $\mathrm{Al}_{2} \mathrm{O}_{3}$ composites feature the lowest fracture energy values $[16,55]$.

\subsubsection{The role of the matrix: Al-Cu matrix composites}

The $J-R$ curves of two different $\mathrm{Al}-\mathrm{Cu} 2 \%$ matrix composites are shown in Fig. 5c: one reinforced with $15 \mu \mathrm{m}$ polygonal particles (A2C-15p) and one reinforced with $60 \mu \mathrm{m}$ angular particles (A2C-A60a). There is again a clear distinction in the fracture properties depending on the reinforcement type. For the angular particle reinforced composite, unstable fracture occurs at the peak load (the fracture point is marked with a circle on the plot). $R$-curve behaviour by ductile tearing is therefore not observed. The fracture behaviour of polygonal $\mathrm{Al}_{2} \mathrm{O}_{3}$-reinforced composites is markedly different: an onset of ductile tearing is detected in such composites, and the critical fracture energy is almost three times that of angular $\mathrm{Al}_{2} \mathrm{O}_{3}$-reinforced composites. In Fig. 5c, the curves are also compared with that for a pure Al matrix composite reinforced with $15 \mu \mathrm{m}$ polygonal particles. The main influence of matrix alloying appears in the ductile tearing region, since unstable fracture occurs in this regime with the alloyed matrix whereas the crack propagates in a fully stable manner with a pure $\mathrm{Al}$ matrix. The critical value $J_{\mathrm{GT}}$ is, on the other hand, only slightly reduced with the $\mathrm{Al}-\mathrm{Cu} 2 \%$ matrix.

The values of the critical fracture energy reported in Table 3 for the Al-Cu matrix composites are $J_{\mathrm{GT}}$ for the A2C-15p composite, and the $J$-value at the instant of fracture instability for the A2C-A60a composite.

\subsection{Photoelastic patterns of the crack-tip plastic zone}

As mentioned earlier, coatings of two thicknesses were used. Their fringe orders and the corresponding shear strain values are given in table in Appendix A. The reader is referred to this table for further detail concerning all photoelasticity figures presented here.

\subsubsection{Evolution of crack-tip strain fields during loading}

The evolution of the crack-tip strain field in the course of a $J$-integral fracture test is presented in Fig. 6 for an A-A35a composite specimen. The load-displacement plot and its related $J-R$ curve are given in Fig. $6 \mathrm{a}$ and $\mathrm{b}$, respectively, where the instants of image acquisition are also indicated. The evolution of photoelastic patterns is presented in Fig. $6 \mathrm{c}-\mathrm{n}$. On each picture, the load and the computed $J$-value are indicated as well. The boundary between the plastic zone and the elastic field is somewhat arbitrary, 

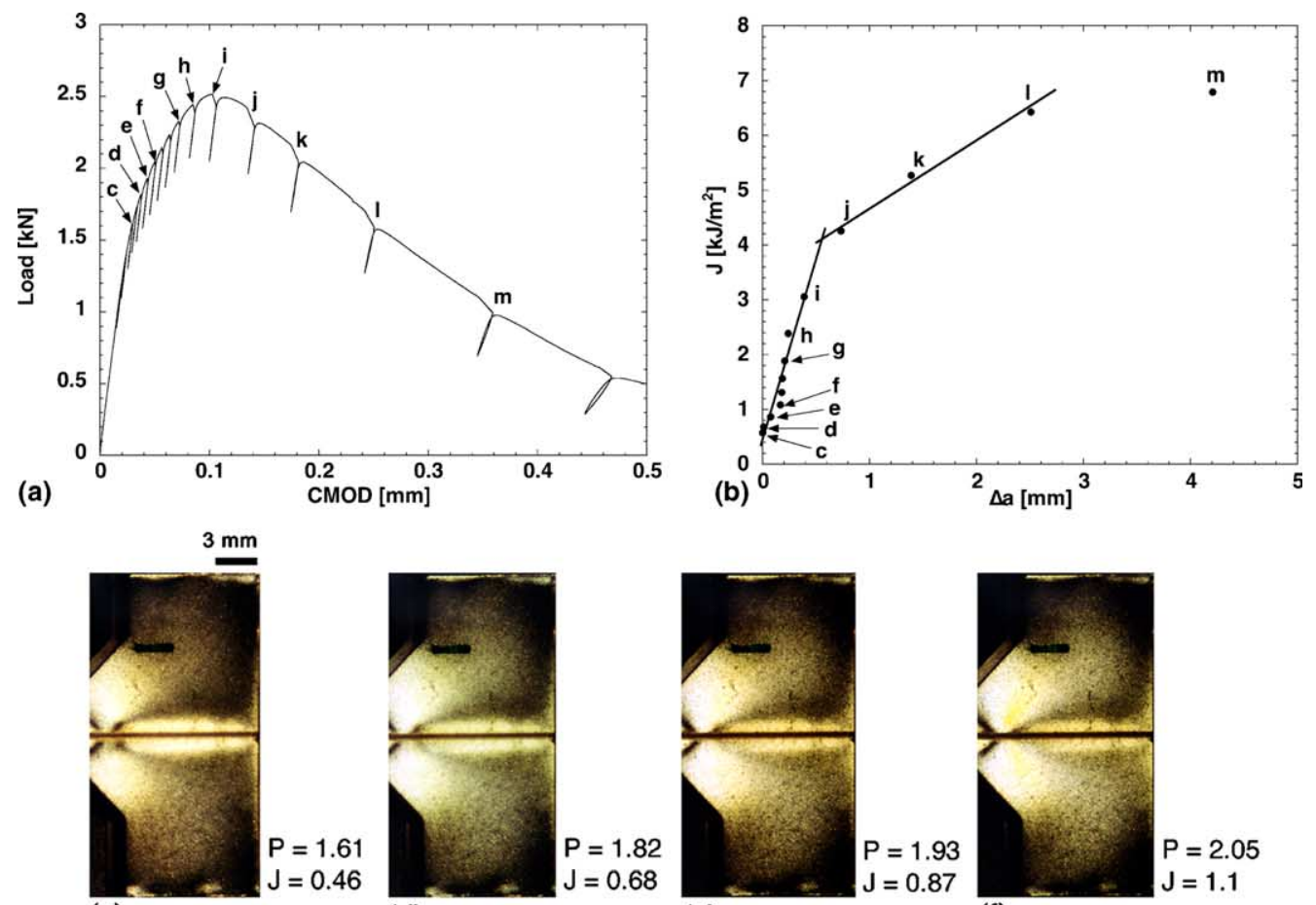

(c)

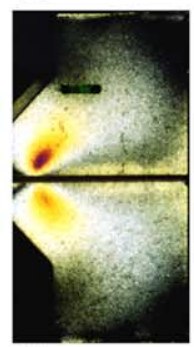

(g)

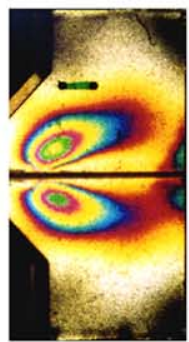

(k)

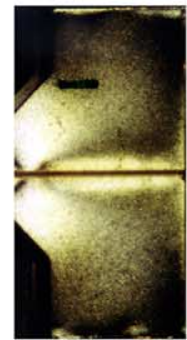

(d)

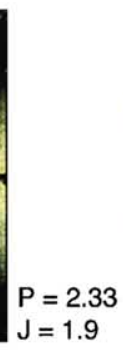

(h)

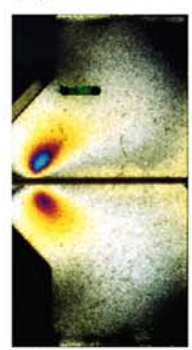

(h)
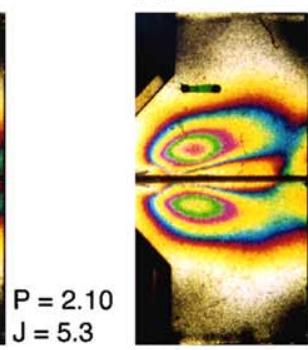

(I)

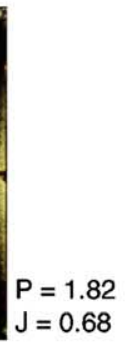

$J=0.68$

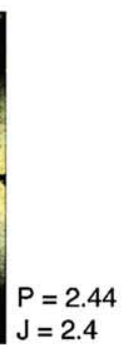

(e)

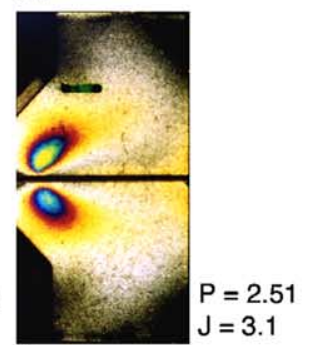

(i)

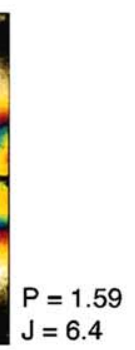

$J=6.4$

$(\mathrm{m})$

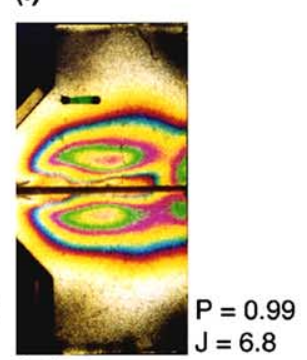

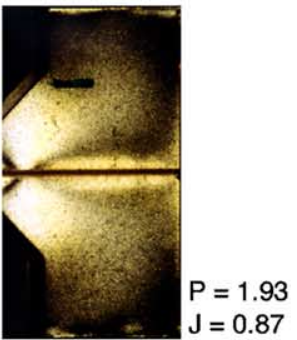

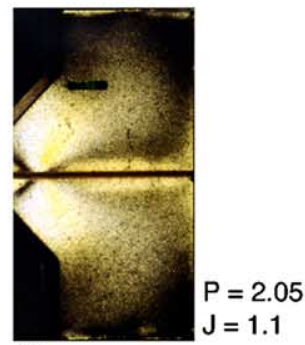

(f)

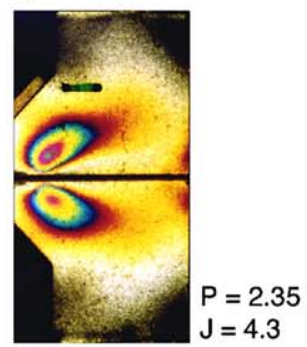

(j)

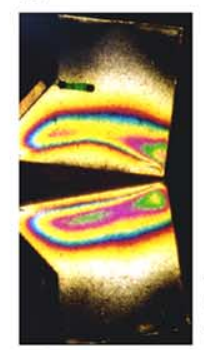

After complete fracture

(n)

Fig. 6. Photoelastic patterns of the surface crack-tip strain fields $\left(\varepsilon_{1}-\varepsilon_{2}\right)$ during $J$-integral testing on the A-A35a composite. (a) LoadCMOD curve; (b) corresponding $J-R$ curve; (c-m) strain fields at the instants indicated on (a) and (b); (n) residual plastic strain field in the CT specimen after complete fracture. Load $(P)$ in $\mathrm{kN}, J$ in $\mathrm{kJ} / \mathrm{m}^{2}$.

especially because no clear yield point can be detected during tensile testing for these composites [45,56]. To guide the discussion, we focus attention on the locus where $\varepsilon_{1}-\varepsilon_{2}$ exceeds $0.2 \%$ strain, and track this as 

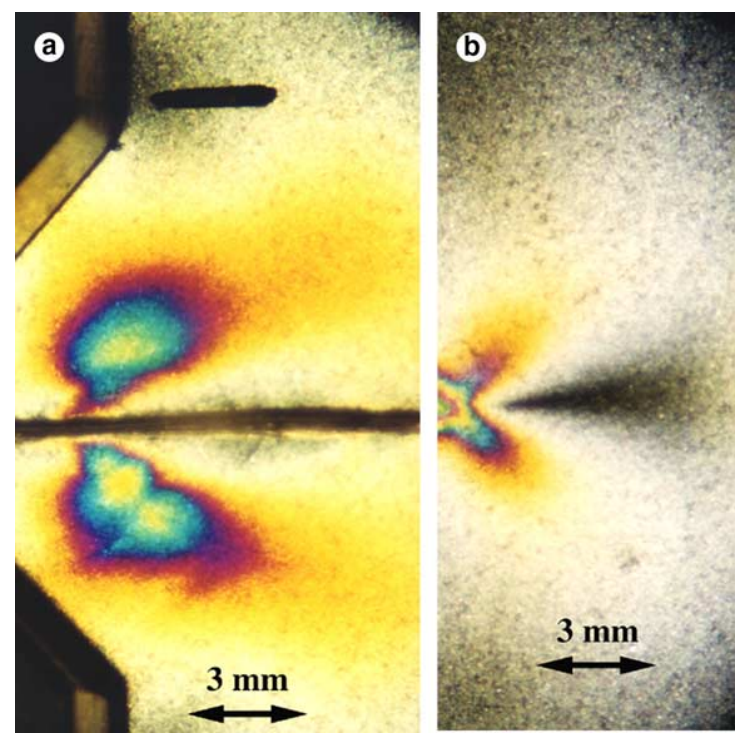

Fig. 7. Crack-tip strain fields in $\mathrm{Al} / \mathrm{Al}_{2} \mathrm{O}_{3}$ polygonal composites at loading conditions close to $J_{\mathrm{GT}}$ : (a) $15 \mu \mathrm{m}$ particles composite, $J=5.7 \mathrm{~kJ} / \mathrm{m}^{2}$; (b) $5 \mu \mathrm{m}$ particles composite, $J=3 \mathrm{~kJ} / \mathrm{m}^{2}$. Observations performed with the $0.5 \mathrm{~mm}$ coating.

showing roughly the outer boundary of the crack-tip plastic zone. As seen in table in Appendix A, for the $0.5 \mathrm{~mm}$ thick coating this corresponds approximately to the first orange fringe (between the pale yellow and the red fringes ${ }^{1}$ ): the plastic zone begins to form while the $J-R$ curve is still in its initial steeper part.

As loading progresses, one notices that critical events occur between $(\mathrm{g})$ and $(\mathrm{j})$, that is, when the load approaches its peak value and then decreases. This corresponds on the $J-R$ curve to the change from process zone formation (region I) to macroscopic crack growth (region II). At (i), namely on the last point of the initial portion of the $J-R$ curve, it is reasonable to consider elastic-plastic conditions at the crack tip. At (j), large-scale yielding sets in. The crack has then propagated significantly and $J$-dominance is lost. The plastic zone then progresses along the remaining ligament, and links with the plastic zone on the backside of the specimen to form a plastic hinge $(\mathrm{k}-\mathrm{m})$. The photoelastic pattern after final failure, shown in Fig. $6 \mathrm{n}$, illustrates the important level of residual plastic strains in the composite, with strains exceeding $1 \%$ in the highly deformed regions (the maximum sustainable strain in the photoelastic coating is exceeded in some regions).

The photoelastic pictures shown in Fig. 6 were acquired with a slitted coating. Other observations with non-slitted coatings [55] revealed equivalent patterns. Both types of coating were therefore used to compare the amount of plastic deformation in the different composites.

\subsubsection{Plastic zone size at the critical fracture event}

The composites presented are those for which $J-R$ curves have been shown in Fig. 5. In all cases, the photoelastic patterns were acquired at load levels close to $J_{\mathrm{GT}}$, namely close to the onset of macroscopic ductile tearing, or slightly before unstable fracture in the case of brittle behaviour.

Crack-tip plastic zones in polygonal particle reinforced composites are presented in Fig. $7 \mathrm{a}$ for the $15 \mu \mathrm{m}$ and in Fig. $7 \mathrm{~b}$ for the $5 \mu \mathrm{m}$ particle composite. Clearly the A-A15p composite is characterised by a much

\footnotetext{
${ }^{1}$ For interpretation of color in Fig. 6, the reader is referred to the web version of this article.
} 
larger plastic zone than the A-A5p composite. Photoelastic patterns of $\mathrm{B}_{4} \mathrm{C}$ reinforced composites (again at the onset of ductile tearing) are shown in Fig. 8; these confirm the previous observation. In the A-B60 composite (Fig. 8a), the plastic zone has already spread over a large part of the specimen while it is more confined for the A-B10 composite (Fig. 8b).

Crack-tip strain fields for Al-Cu2\% matrix composites are given in Fig. 9. Here the images were acquired using the thicker $1 \mathrm{~mm}$ coating (which has a better strain resolution but a lower maximum measurable

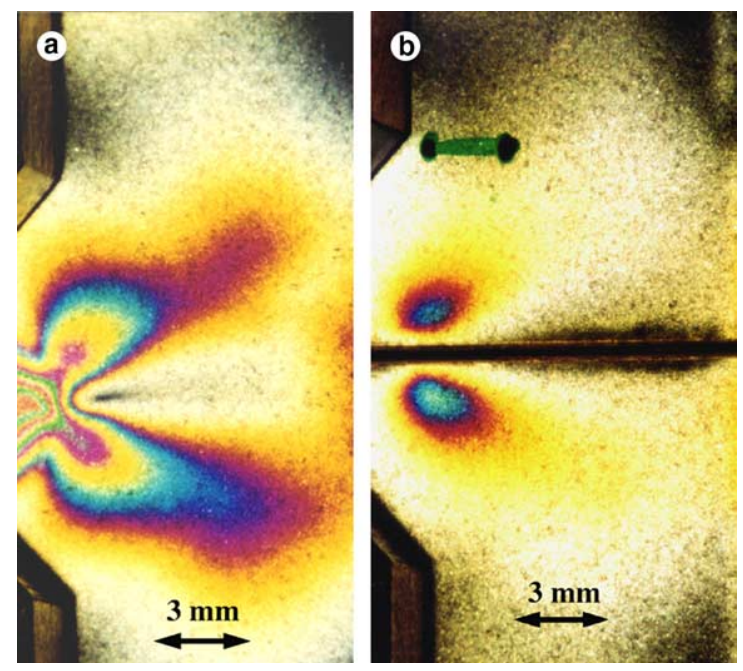

Fig. 8. Crack-tip strain fields in $\mathrm{A} 1 / \mathrm{B}_{4} \mathrm{C}$ composites at loading conditions close to $J_{\mathrm{GT}}$ : (a) $60 \mu \mathrm{m}$ particles composite, $J=6.5 \mathrm{~kJ} / \mathrm{m}^{2}$; (b) $10 \mu \mathrm{m}$ particles composite, $J=2.9 \mathrm{~kJ} / \mathrm{m}^{2}$. Observations performed with the $0.5 \mathrm{~mm}$ coating.

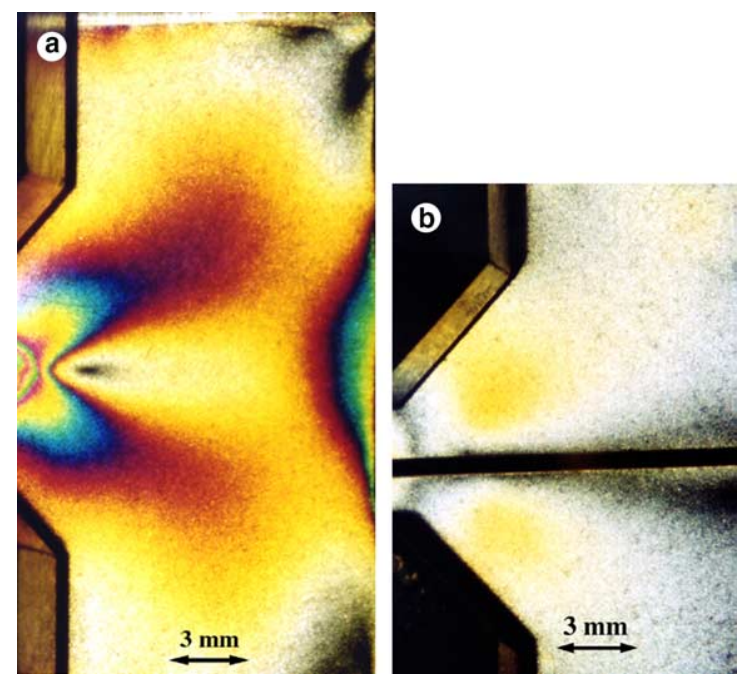

Fig. 9. Crack-tip strain fields in $\mathrm{Al}-\mathrm{Cu} 2 \%$ matrix composites at loading conditions close to $J_{\mathrm{GT}}$ : (a) $15 \mu \mathrm{m} \mathrm{Al}_{2} \mathrm{O}_{3}$ polygonal particles composite, $J=4.4 \mathrm{~kJ} / \mathrm{m}^{2}$; (b) $60 \mu \mathrm{m}$ angular $\mathrm{Al}_{2} \mathrm{O}_{3}$ particles composite, $J=1.5 \mathrm{~kJ} / \mathrm{m}^{2}$. Observations performed with the $1.1 \mathrm{~mm}$ coating. 
strain). According to the previous definition, the boundary of the plastic zone coincides with the blue-green fringe for this coating thickness. In the A2C-A15p composite (Fig. 9a) a distinct plastic zone has developed at the crack tip. In the A2C-A60a composite (Fig. 9b) on the other hand, no distinct plastic zone is observed in front of the crack tip prior to fracture (the picture in Fig. 9b was acquired just before unstable fracture). Fracture is $K$-dominated and an $R$-curve associated with plastic dissipation is not measured (see Fig. $5 \mathrm{c}$ ).

To summarize the data, the composites shown in this study can roughly be grouped into three classes. In the first are the composites with a large plastic zone size and wake; among them one finds pure $\mathrm{Al}$ matrix composites reinforced with medium and large particles (i.e., $35 \mu \mathrm{m}$ angular $\mathrm{Al}_{2} \mathrm{O}_{3}, 15 \mu \mathrm{m}$ polygonal $\mathrm{Al}_{2} \mathrm{O}_{3}$, and $60 \mu \mathrm{m} \mathrm{B}_{4} \mathrm{C}$ ). These all present rather marked $R$-curve behaviour. In the second class are the composites with a more limited $R$-curve behaviour, and for which a smaller plastic zone size is formed. These are the pure $\mathrm{Al}$ matrix composites with smaller particles $\left(5 \mu \mathrm{m} \mathrm{Al}_{2} \mathrm{O}_{3}\right.$ polygonal and $\left.10 \mu \mathrm{m} \mathrm{B}_{4} \mathrm{C}\right)$, as well as the $\mathrm{Al}-\mathrm{Cu} 2 \%$ matrix composites reinforced with $15 \mu \mathrm{m}$ polygonal particles. The third group comprises the zcomposites with the lowest fracture energy, namely the $\mathrm{Al}-\mathrm{Cu} 2 \%$ matrix composite reinforced with 60 $\mu \mathrm{m}$ angular particles; here a distinct plastic zone is not formed during crack propagation.

\section{Discussion}

\subsection{Comparison between experimental and computed F-CMOD and J-CMOD curves}

The experimental $F-$ CMOD and $J$-CMOD plots for two composites (A-A15p and A2C-A15p) are compared with FE computations in Fig. 10. Since damage and crack motion are not taken into account in the calculation, the computed F-CMOD curves (Fig. 10a and c) lie somewhat above the experimental curves beyond the elastic domain.

For crack length $a_{1}$ (corresponding in the experiment to the instant of photoelastic observations), the computed load decreases but still remains slightly too high at the corresponding experimental crack length. We attribute this mainly to viscoplastic effects, which are not accounted for in the FE formulation. Such behaviour is indeed visible on the experimental curve before each unloading cycle (Fig. 10a). Since the tests were temporarily interrupted to allow the acquisition of the photoelastic patterns, relaxation occurred during this time, in particular with the softer pure Al matrix composites. Relaxation is less pronounced in Al- $\mathrm{Cu}$ matrix composite (Fig. 10c), and indeed the computed $F-\mathrm{CMOD}$ curve for the crack length $a / W=0.48$ predicts a load closer to experiment.

The contour plots of the strain fields are compared at equivalent values of $J$. As can be seen in Fig. 10b for the pure Al matrix composites, the computed $J-C M O D$ curves correlate well with the experimental curves. The correlation is even better for the Al-Cu matrix composite (Fig. 10d): experimental and simulated values of $J$ are exactly superimposed for $a / W=0.48$.

The strain fields computed with the initial crack length $a_{0}$ are almost identical with those computed for a crack length $a_{1}$ (for the same value of $J$ ). Therefore, we present for simplicity the crack-tip fields as calculated for one crack length only, namely the instantaneous crack length $a_{1}$ at the moment of experimental observation. Values of CMOD, $P$ and $J$ at which crack-tip strain fields were computed are indicated in Table 4.

\subsection{Comparison of observed, HRR, and FE fields}

The precision of the photoelastic measurements might become corrupted if important out-of-plane displacements due to lateral specimen contraction disturb the planarity of the observed surface. In that case, the local inclination and/or bending of the photoelastic film could lead to erroneous readings. Such an effect can be anticipated for extremely ductile materials. Here, the observed specimen contraction is very 

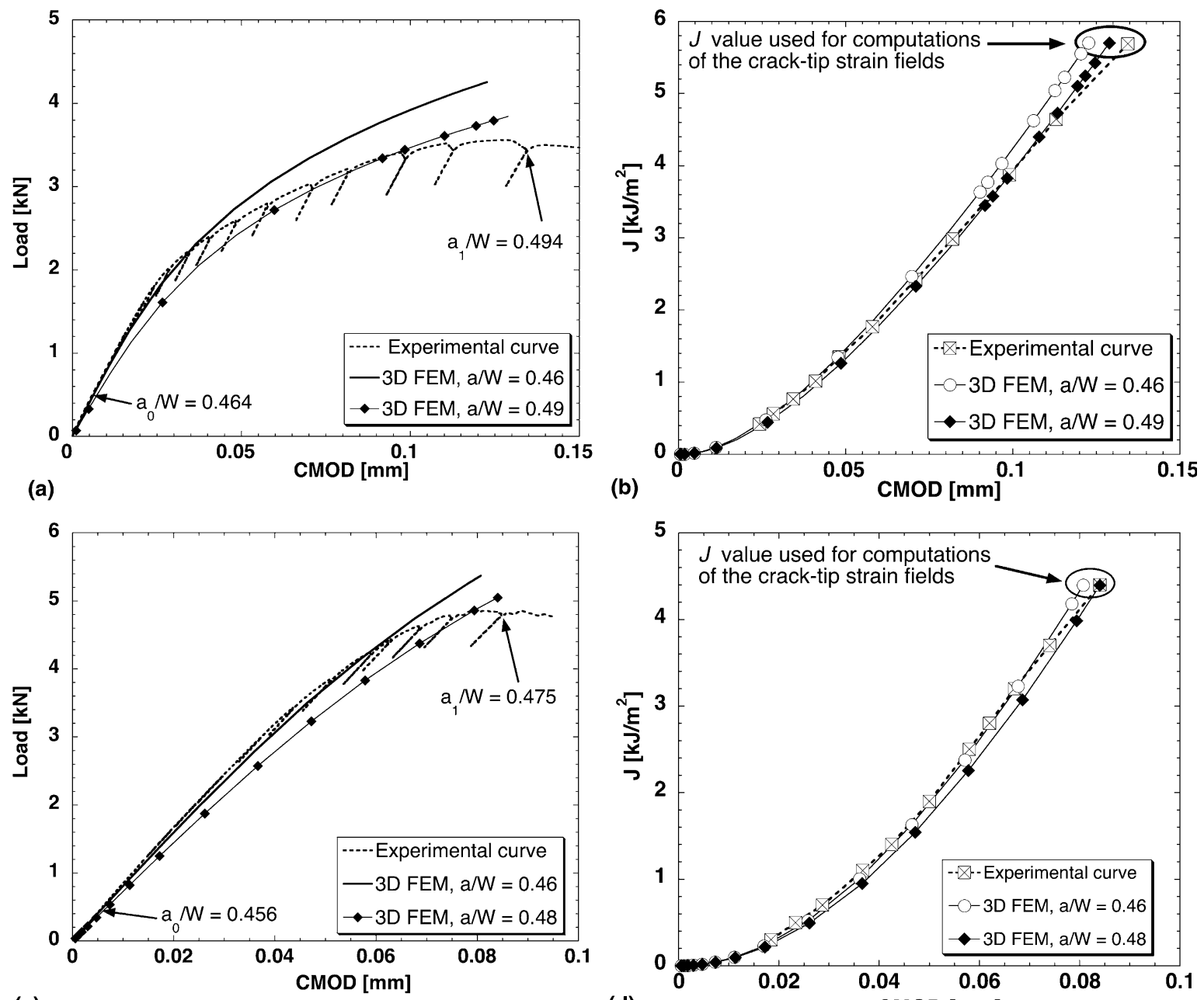

(b)

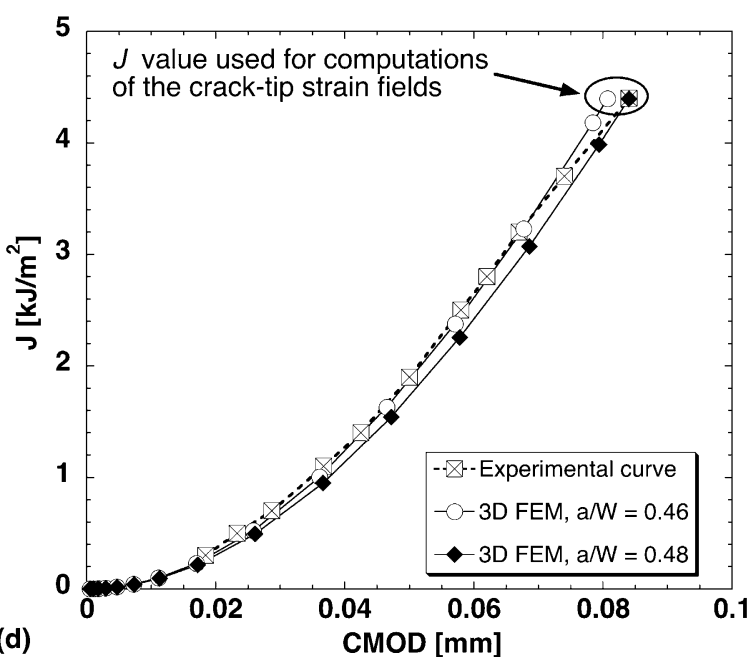

Fig. 10. Load-CMOD and $J-C M O D$ curves, comparison between experiments and FE analysis: (a and b) A-A15p composite; (c and d) A2C-A15p composite. The crack-tip strain fields of the CT specimens are computed at $J$ values matching those at the instants of the photoelastic observations. These $J$ and the corresponding $P$ values are indicated on the plots.

Table 4

Input data for the computations of strain fields

\begin{tabular}{|c|c|c|c|c|c|c|c|}
\hline \multirow[t]{2}{*}{ Composite } & \multirow{2}{*}{$\begin{array}{l}\text { Crack length } \\
a / W\end{array}$} & \multicolumn{2}{|c|}{ CMOD $(\mathrm{mm})$} & \multicolumn{2}{|c|}{ Load $(\mathrm{kN})$} & \multicolumn{2}{|c|}{$J\left(\mathrm{~kJ} / \mathrm{m}^{2}\right)$} \\
\hline & & Exp. & Calc. & Exp. & Calc. & Exp. & Calc. \\
\hline \multirow[t]{2}{*}{ A-A15p } & $0.46^{\mathrm{a}}$ & - & 0.1227 & - & 4.26 & - & 5.7 \\
\hline & $0.49^{\mathrm{b}}$ & 0.1344 & 0.1289 & 3.45 & 3.84 & 5.7 & 5.7 \\
\hline \multirow[t]{2}{*}{ A2C-A $15 p$} & $0.46^{\mathrm{a}}$ & - & 0.0807 & - & 5.37 & - & 4.4 \\
\hline & $0.48^{\mathrm{b}}$ & 0.0848 & 0.0840 & 4.80 & 5.05 & 4.4 & 4.4 \\
\hline
\end{tabular}

The strains fields presented in Figs. 11 and 12 were computed with FEA for crack length $a_{1}$ (at the instant of photoelastic observations).

${ }^{\text {a }}$ Initial crack length $\left(a_{0} / W\right)$, calculated from the initial experimental compliance.

${ }^{\mathrm{b}}$ Crack length $\left(a_{1} / W\right)$ at the instant of photoelastic observations, i.e. close to peak load and $J_{\mathrm{GT}}$. 
small. FE analysis confirms that the local out-of-plane displacement at the crack tip is below $20 \mu \mathrm{m}$. Hence, the surface inclination at the elastic-plastic interface is on the order of $1 \mathrm{mrad}$ and such artefacts can be excluded.

The crack-tip strain fields computed with the HRR solution and with the FE simulations are presented in Fig. 11b-d for the A-A15p composite (pure Al matrix), and compared with the experimentally observed fields (Fig. 11a). For the pure Al matrix composites, the plane-stress HRR fields (Fig. 11b) describe reasonably well the experiments for the largest strain values shown in the plots. In particular, at angles situated at approximately $30-60^{\circ}$ from the crack plane, the isostrain values are close to the experimentally measured ones. Correlation remains, nevertheless, incomplete: clearly, the experimental plastic zone contour (the lower strain fringes) is "attracted" towards the back of the specimen, such that the plastic zone is elongated parallel to the crack plane. This feature is obviously not captured by the HRR analysis since it does not account for finite boundary conditions. Note that such a plastic zone shape is also clearly visible on the experimental field of the A-B60 composite (Fig. 8a).

The FEM contour lines on the surface of the 3-D model (Fig. 11c), on the other hand, describe well the experimental strain fields: the plastic zone is well predicted for the pure Al matrix composite. The plastic zone on the back of the specimen is also observed with the 3-D computations. Quantitative values of the shear strain (given by the colour index indicated on the figures) also fits well the observed values over the entire plastic zone.

The plastic zone on the back of the specimen is clearly overestimated by the 2-D plane-stress FE analysis, whereas the crack-tip plastic zone is obviously too small as compared to experiment. This points out the

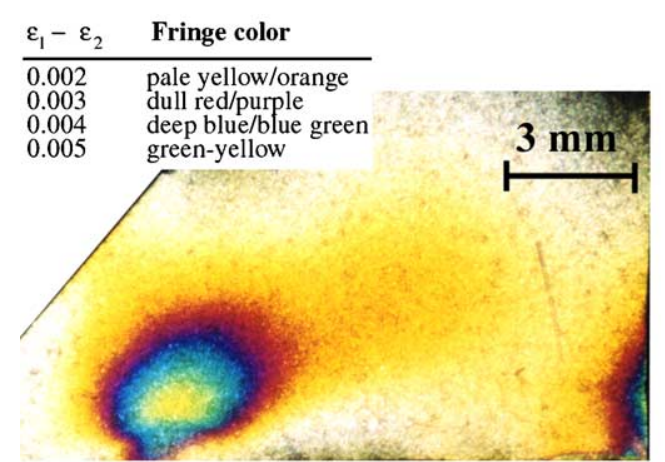

(a)

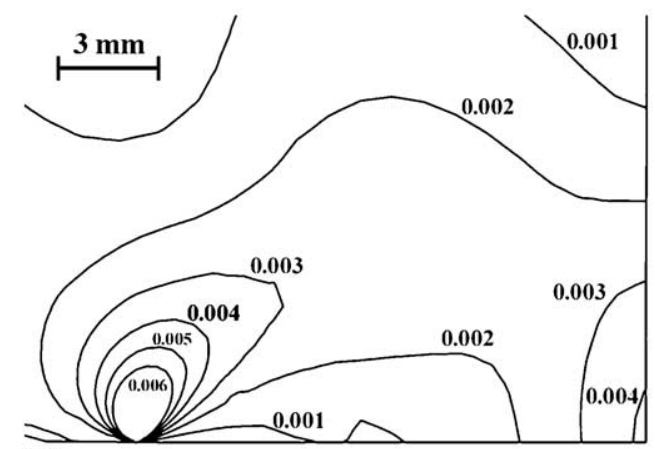

(c)

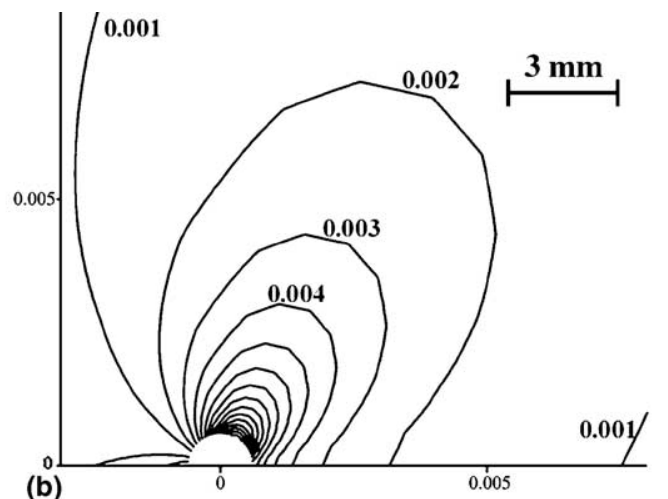

(b)

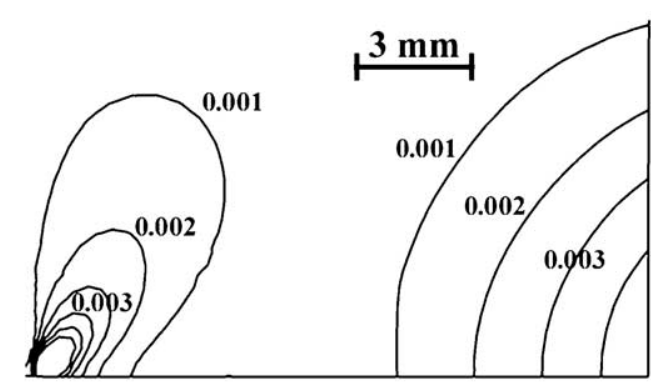

(d)

Fig. 11. Crack-tip strain fields $\left(\varepsilon_{1}-\varepsilon_{2}\right)$ on the surface of the A-A $15 \mathrm{p}$ composite at $J=5.7 \mathrm{~kJ} / \mathrm{m}^{2}$ : (a) observed field ( $0.5 \mathrm{~mm}$ coating); (b) HRR field in plane stress; (c) FE analysis, surface of the 3-D model; (d) FE analysis, 2-D model, plane stress. 
importance of three-dimensional effects in determining the plastic zone size on the specimen surface: for the same loading conditions, 2-D plane-stress computation yields a much smaller crack-tip plastic zone than the 3-D computation. Two reasons can be invoked to explain this difference. Firstly, lateral contraction relaxes the stresses on the surface of a 3-D sample, thus leading to a fairly homogeneous strain distribution, whereas strains are strongly localised in plane stress. The close spacing of contour lines in Fig. 11d indicates these strong gradients. The peak strain in the first element at the crack tip is roughly six times higher in plane stress than on the surface of a 3-D sample. Secondly, the finite size of the sample induces a considerable strain localisation also on the back of the sample in plane stress, an effect that is again less pronounced in 3-D.

Another feature that is better captured by the 3-D FE simulations is the shape of the contour lines along the crack plane. From the experimental observations, one sees that the isostrain contour lines meet close to the crack tip. On the surface of the computed 3-D specimen, the same feature is observed. This is not described by the plane-stress HRR field, in particular for the low strain fringes, nor by the 2-D plane-stress FE simulation (Fig. 11d).

Comparison between experimental and computed fields for (stronger) $\mathrm{Al}-\mathrm{Cu}$ matrix composites is presented in Fig. 12. A word of caution is necessary for this specimen: because the bond strength between the photoelastic coating and the specimen was not as strong as with pure Al matrix composites, debonding

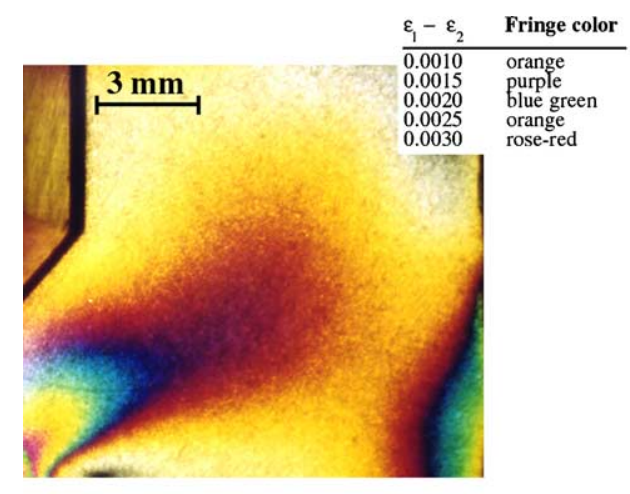

(a)
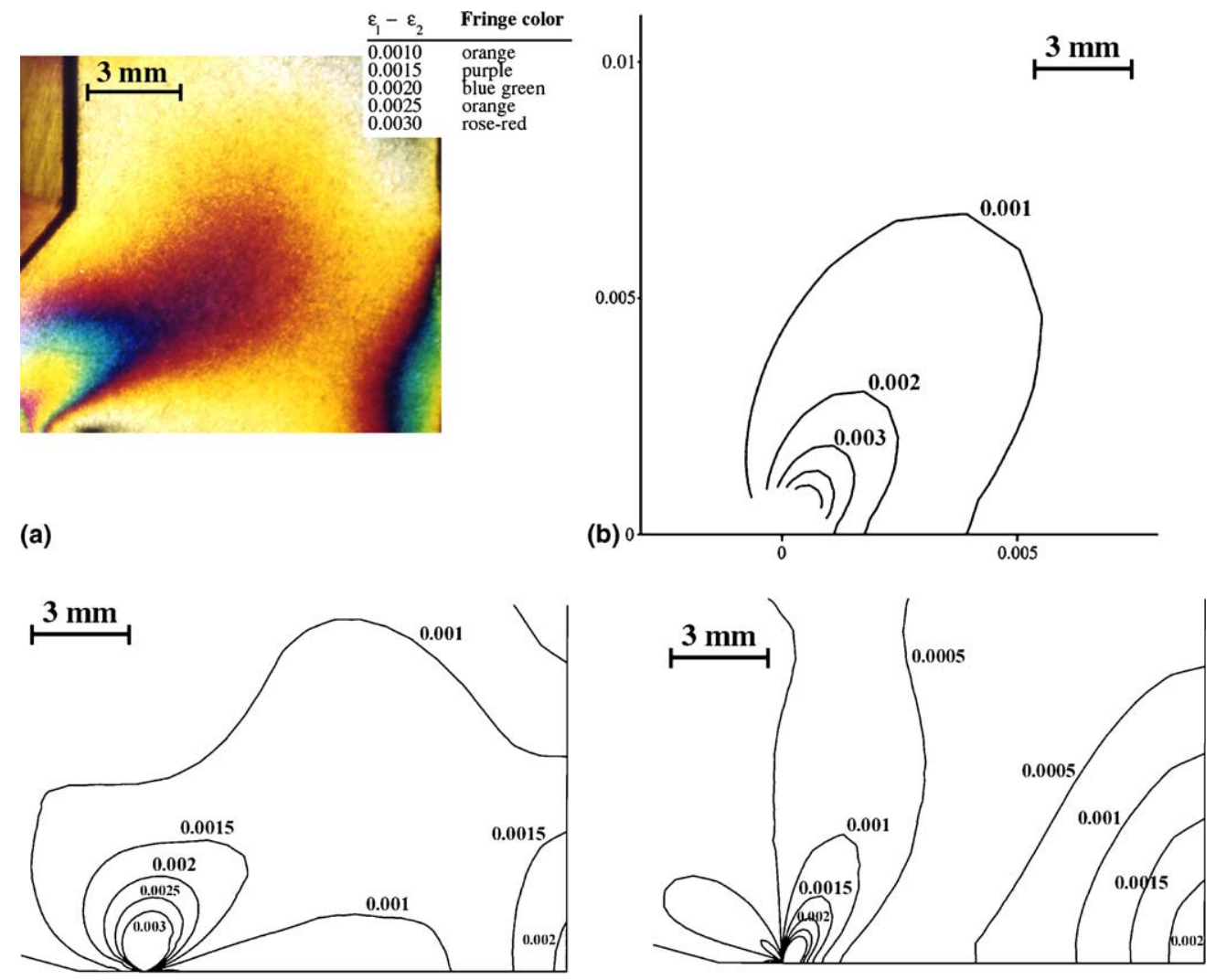

(c)

(d)

Fig. 12. Crack-tip strain fields $\left(\varepsilon_{1}-\varepsilon_{2}\right)$ on the surface of the A2C-A15p composite at $J=4.4 \mathrm{~kJ} / \mathrm{m}^{2}$ : (a) observed field (1.1 mm coating); (b) HRR field in plane stress; (c) FEM, surface of the 3-D specimen; (d) FEM, 2-D specimen, plane stress. 
occurred when machining the middle of the photoelastic coating in the crack plane. Hence, photoelastic investigations on non-slitted coatings are used for comparison (Fig. 12a), which somewhat perturbs the photoelastic response behind the crack tip. Farther from the tip on the other hand, observations remain reliable.

As seen in Fig. 12c, the description of experimental crack-tip fields by the 3-D FE analysis is again very satisfying. As above, the HRR solution (Fig. 12b) provides a better description of the crack-tip field than the plane-stress 2-D FE simulation (Fig. 12d). The higher yield strength of the composite has the expected effect that strain contours are not so much attracted by the backside of the specimen as for pure Al matrix composites (compare with larger strain contours in Fig. 12c). The appearance of the plastic hinge is obviously delayed, which is also the reason why the HRR solution provides a reasonable approximation of the near-tip field. Still, purely plane-stress conditions do not exist on the surface.

Taken together, comparisons of observed crack-tip strain fields on the specimen surface and FE computations clearly illustrate the importance of three-dimensional constraint effects: only the 3-D analysis successfully describes the experimental observations at a given value of $J$. This confirms an earlier review by Parks [28] and agrees with the results discussed in [20,30,31] where FE analyses were compared with CTOA or CTOD measurements.

\subsection{Plastic zone size}

From Figs. 6-9 and Table 3, it is visible that $J$ correlates with the plastic zone size: for pure Al matrix composites for instance, the tougher materials (higher $J_{\mathrm{GT}}$ values) exhibit a larger plastic zone. This is expected since according to elementary EPFM theory the plastic zone size, $r_{y}$ is approximately given by

$$
r_{y} \approx \alpha \frac{J E}{\sigma_{y}^{2}}
$$

where $\alpha$ is a dimensionless parameter that depends on the state of stress in the specimen. Verification of Eq. (2) during loading for the A-A35a composite (Fig. 6c-n) is shown in Fig. 13, by plotting $r_{y}$ vs. $J E /\left(\sigma_{y}\right)^{2}$ (solid symbols). As mentioned earlier, the external boundary of the plastic zone is of necessity somewhat

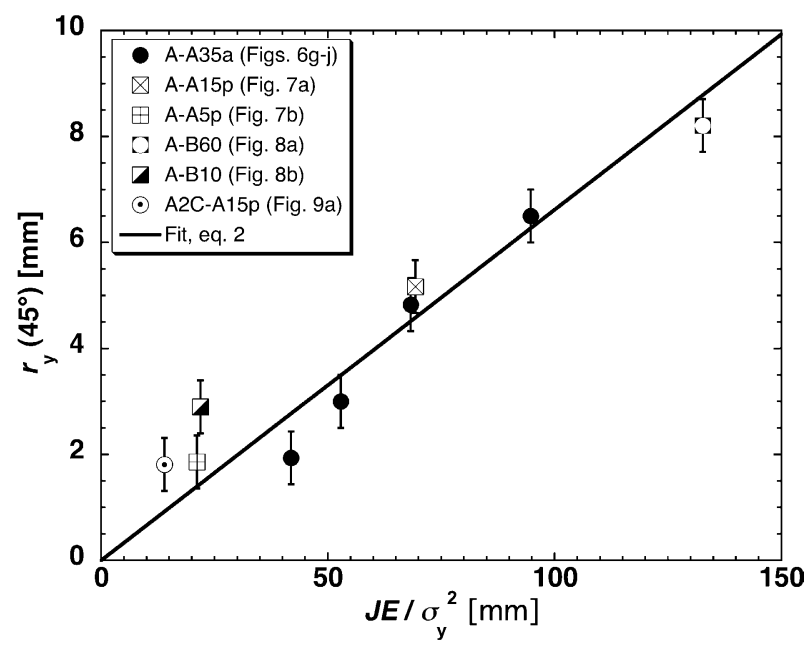

Fig. 13. Plastic zone size $r_{y}$ (defined at $\varepsilon_{1}-\varepsilon_{2} \approx 0.2 \%$ and measured at an angle $\theta$ of $45^{\circ}$ from the crack plane) vs. $J E / \sigma_{y}^{2}$. Solid circles represent the evolution of strain fields with loading in one composite (Fig. $6 \mathrm{~g}-\mathrm{j}$ ), whereas other symbols correspond to the instant of observations presented in Figs. 7-9 for various composites. The linear correlation of $r_{y}$ with $J E / \sigma_{y}^{2}$ is confirmed. 
arbitrarily defined. Here, $r_{y}$ is estimated according to the definition given in Section 4.2.1 (orange fringe for the thin coating and blue-green fringe for the thick coating). In addition, $r_{y}$ is measured at an angle $\theta$ of $45^{\circ}$ from the crack plane. Up to the onset of large scale yielding conditions (i.e. until Fig. 6j), the linear correlation between $r_{y}$ and $J E /\left(\sigma_{y}\right)^{2}$ is confirmed. Similar data for the different composites at the instant of observations (Figs. 7-9) are also included in Fig. 13. Within the uncertainty in the experimental determination of $r_{y}$ (sources of which include the exact position of the crack tip and the width of fringes used to infer the plastic zone boundary), scaling of the plastic zone size with $J E /\left(\sigma_{y}\right)^{2}$ is corroborated. We also note that the value of $\alpha$ (Eq. (2)) obtained by fitting the data is 0.067: this is between the plane stress $(1 / 2 \pi \approx 0.16)$ and the plane strain $(1 / 6 \pi \approx 0.053)$ values obtained with the simple Irwin analysis in smallscale yielding. Care must, however, be exercised with the meaning of this value, given the somewhat arbitrary definition of the experimental plastic zone radius (dependent on the selected fringe value and the $\theta$ angle of $45^{\circ}$ ), and also given the fact that, even along the sample surface, the strain field is not in a pure plane-stress condition (see Section 5.2).

\subsection{Toughening in high volume fraction ceramic particle MMCs}

From Figs. 6-9, it follows that, despite the high ceramic loadings, the toughness of these composites is mostly a result of plastic dissipation in front of the crack tip, a finding that can already be inferred from the characteristics of the $J-R$ curves. Early comments by Davidson for composites with a lower volume fraction of reinforcements (15-20 vol.\%) are thus confirmed. A second characteristic of these composites is a corollary of the first observation, namely that the plastic zone size at the onset of macroscopic crack growth is a material parameter that can be used to compare the different composites.

It is also seen that a large spectrum of composite toughness values and crack-tip plasticity levels is covered by variation of the composite constituents' nature and size. All else being constant, the intrinsic characteristics of the ceramic particles are crucial in the view of obtaining tough composites. For instance, changing the reinforcement type from angular to polygonal in $\mathrm{Al}-\mathrm{Cu}$ matrix composites changes the global behaviour from brittle to ductile. The size of the reinforcement exerts an important role too, as shown for the pure $\mathrm{Al}$ matrix composites, which is as expected [57]. The next step towards a more fundamental understanding of the toughness of these materials is to investigate the micromechanisms of damage and failure: their incorporation into FE analysis via realistic models may open the way towards predicting the fracture toughness of these materials as a function of their main microstructural parameters.

\section{Conclusions}

From fracture toughness characterisation coupled with direct observations of surface crack-tip strain fields using photoelasticity and comparison with numerical simulations, two main conclusions are drawn:

- Despite the presence of more than 50 vol.\% of ceramic reinforcement, the main contribution to toughness in infiltrated alumina and boron carbide particle reinforced aluminium is plastic dissipation in front of the crack tip. The crack-tip plastic zone is finite and increases with composite toughness: the larger the plastic zone, the larger the critical $J$ value for the onset of crack growth $J_{\mathrm{GT}}$. This plastic zone is governed by microstructural factors; for a roughly constant volume fraction of reinforcement, the intrinsic particle characteristics and their average sizes strongly influence the plastic zone size and, in turn, the composite toughness. The role of the matrix is equally important; increasing the matrix yield strength leads to a decrease in the plastic zone size; however, this a priori detrimental effect on toughness can be compensated by the larger composite flow stress, provided that high-quality reinforcement is used. 
- The plastic zone size and shape are well described by the strain fields modelled from the elastic-plastic properties of the composites, provided that a full 3-D FE analysis of the real specimen is carried out. Neither the analytical HRR field nor 2-D plane-stress FE analysis capture the experimentally determined fields with satisfactory precision. This is important to consider if experimental crack-tip strain field acquisitions are used in order to infer stress intensity factors with such elastic-plastic materials.

\section{Acknowledgements}

This work was funded by the Swiss National Science Foundation under contract-no. 2000-063575-00, with added support from core funding of the Swiss Federal Institute of Technology, Lausanne.

\section{Appendix A}

Isochromatic fringe characteristics of the photoelastic coatings, given in terms of the shear strain component $\varepsilon_{1}-\varepsilon_{2}$

\begin{tabular}{llll}
\hline Color & Fringe order $N$ & $0.5 \mathrm{~mm}$ coating thickness & $1.1 \mathrm{~mm}$ coating thickness \\
& & $\varepsilon_{1}-\varepsilon_{2}(\%)$ & $\varepsilon_{1}-\varepsilon_{2}(\%)$ \\
\hline Black & 0.00 & 0.00 & 0.00 \\
Gray & 0.18 & 0.07 & 0.03 \\
White & 0.25 & 0.09 & 0.04 \\
Pale yellow & 0.39 & 0.15 & 0.07 \\
Orange & 0.57 & 0.22 & 0.10 \\
Dull red & 0.71 & 0.27 & 0.12 \\
Purple & 0.86 & 0.33 & 0.15 \\
Deep blue & 1.00 & 0.38 & 0.17 \\
Blue-green & 1.13 & 0.43 & 0.19 \\
Green-yellow & 1.23 & 0.47 & 0.21 \\
Orange & 1.43 & 0.54 & 0.25 \\
Rose-red & 1.66 & 0.63 & 0.29 \\
Rose & 1.84 & 0.70 & 0.32 \\
Purple & 1.96 & 0.74 & 0.34 \\
Green & 2.11 & 0.80 & 0.36 \\
Green-yellow & 2.48 & 0.94 & 0.43 \\
Red & 2.71 & 1.03 & 0.47 \\
Red/green transition & 3.05 & 1.16 & 0.53 \\
Green & 3.21 & 1.22 & 0.55 \\
Pink & 3.66 & 1.39 & 0.63 \\
Pink/green transition & 4.16 & 1.58 & 0.72 \\
Green & 4.38 & 1.66 & 0.75 \\
\hline
\end{tabular}

\section{References}

[1] Clyne TW, Withers PJ. In: Ward LM, editor. An introduction to metal matrix composites. Cambridge solid state science series. Cambridge, UK: Cambridge University Press; 1993. 
[2] Clyne TW. An introductory overview of MMC systems, types, and developments. In: Clyne TW, editor. Comprehensive composite materials. Metal Matrix Composites, vol. 3. Amsterdam: Elsevier; 2000. p. 1-26.

[3] Lewandowski JJ. Fracture and fatigue of particulate MMCs. In: Clyne TW, editor. Comprehensive composite materials. Metal matrix composites, vol. 3. Amsterdam: Elsevier; 2000. p. 151-87.

[4] Miracle D. Metallic composites in space: a status report. JOM 2001;April:12-25.

[5] Davidson DL. Fracture characteristics of Al-4\%Mg mechanically alloyed with SiC. Metall Trans 1987;18A(12):2115-28.

[6] Davidson DL, Heness G. The effect of particle shape and volume fraction on matrix deformation and fracture in aluminum composites. In: Proceedings of the Conference on Mechanisms and Mechanics of Composite Fracture, Pittsburgh, PA, ASM International, Materials Park, OH 44073-0002, 1993.

[7] Davidson DL. Fatigue and fracture toughness of aluminium alloys reinforced with $\mathrm{SiC}$ and alumina particles. Composites $1993 ; 24(3): 248-55$.

[8] Flom Y, Arsenault RJ. Effect of particle size on fracture toughness of SiC/Al composite material. Acta Metall 1989;37(9):2413-23.

[9] Hunt WH, Osman TM, Lewandowski JJ. Micro- and macrostructural factors in DRA fracture resistance. JOM 1993;45(1):30-5.

[10] Hunt WH. Particulate reinforced MMCs. In: Clyne TW, editor. Comprehensive composite materials. Metal matrix composites, vol. 3. Amsterdam: Elsevier; 2000. p. 701-15.

[11] Seleznev ML, Argon AS, Seleznev IL, Cornie JA, Mason RP. Effect of composition, particle size and heat treatment on the mechanical properties of $\mathrm{Al}-4.5 \mathrm{wt} . \% \mathrm{Cu}$ based alumina particulate reinforced composites, Paper no. 980 700, SAE Technical Paper Series, 1998.

[12] Pandey AB, Majumdar BS, Miracle DB. Deformation and fracture of particle-reinforced aluminium alloy composites: Part I. Experiments. Metall Mater Trans 2000;31A:921-36.

[13] Davidson DL. Tensile deformation and fracture toughness of $2014+15$ vol. $\%$ SiC particulate composites. Metall Trans 1991;22A(1):113-23.

[14] Klimowicz TF, Vecchio KS. The influence of aging condition on the fracture toughness of alumina-reinforced aluminum composites. In: Proceedings of the Conference on Fundamental Relationships between Microstructure and Mechanical Properties of Metal Matrix Composites, TMS, Indianapolis, IN, 1990.

[15] Lewandowski JJ, Singh PM. Toughness of DRA and extrinsically toughened DRA/aluminium alloy laminates. In: Proceedings of the Conference on Intrinsic and Extrinsic Fracture Mechanisms in Inorganic Composite Systems, The Minerals, Metals \& Materials Society, 1995.

[16] Miserez A, Rossoll A, SanMarchi C, Weber L, Mortensen A. Fracture toughness determination of high volume fraction particle reinforced aluminium matrix composites. In: Proceedings of the Conference on Advances in Mechanical Behaviour, Plasticity and Damage, Euromat 2000, Elsevier, Tours, 2000.

[17] Miserez A, Stücklin S, Rossoll A, Marchi CS, Mortensen A. Influence of heat treatment and particle shape on mechanical properties of infiltrated $\mathrm{Al}_{2} \mathrm{O}_{3}$ particle reinforced Al-2 wt.\%Cu. Mater Sci Technol 2002;18:1461-70.

[18] Chan KS. Crack-tip behaviors of stationary and growing cracks in Al-Fe-X Alloys: Part I. Near-tip strain field. Metall Trans 1990;21A:69-80.

[19] Dadkah MS, Kobayashi AS. HRR field of a moving crack, an experimental analysis. Engng Fract Mech 1989;34(1):253-62.

[20] Wang YY, Parks DM, Lloyd WR, Reuter WG, Epstein J. Elastic-plastic deformation in surface-cracked plates: experiments and numerical analysis. J Appl Mech 1991;58:895-903.

[21] Tay TE, Yap CM, Tay CJ. Crack tip and notch tip plastic zone size measurement by the laser speckle technique. Engng Fract Mech 1995;52(5):879-93.

[22] Wei X, Li J, Zhou X, Ke W. The influence of anodic current on surface and bulk deformation at the crack tip of pure copper in $3.5 \% \mathrm{NaCl}$ solution. Corros Sci 1996;38(6):989-98.

[23] Goulet RU, Gross TS, Mendelsohn DA. Evidence of fracture surface interference for cracks loaded in shear detected by phaseshifted speckle interferometry. Metall Mater Trans 1996;27A:3853-60.

[24] Nurse AD, Patterson EA. Determination of predominantly mode II stress intensity factors from isochromatic data. Fatigue Fract Engng Mater Struct 1993;16(12):1339-54.

[25] Nurse AD, O’Brien EW, Patterson EA. Stress intensity factors for cracks at fastener holes. Fatigue Fract Engng Mater Struct 1994;17(7):791-7.

[26] Picon R, Paris F, Canas J, Marin J. A complete field method for the photoelastic determination of $K_{\mathrm{I}}$ and $K_{\mathrm{II}}$ in general mixedmode fracture. Engng Fract Mech 1995;51(3):505-16.

[27] Ekman MJ, Marsavina L, Nurse AD. Complex fracture parameters for an interface crack between two hardening materials: a photoelastic study. Fatigue Fract Engng Mater Struct 2000;23:619-32.

[28] Parks DM. Three-dimensional aspects of HRR-dominance. In: Proceedings of the Conference of European Symposium on Elastic-Plastic Fracture Mechanics: Defect Assessment in Components-Fundamentals and Applications, Freiburg, Germany, Mechanical Engineering Publications Ltd, London, 1991.

[29] Merkle JG. Patterns and perspectives in applied fracture mechanics. In: Newman JC, editor. Fracture mechanics. ASTM STP 1256, vol. 26. Philadelphia: American Society for Testing and Materials; 1995. p. 3-40. 
[30] Newman JC, James MA, Zerbst U. A review of the CTOA/CTOD fracture criterion. Engng Fract Mech 2003;70:371-85.

[31] Dawicke DS, Newman JC, Bigelow CA. Three-dimensional CTOA and constraint effects during stable tearing in a thin-sheet material. In: Newman JC, editor. Fracture mechanics. ASTM STP 1256, vol. 26. Philadelphia: American Society for Materials and Testing; 1995. p. 223-42.

[32] Gullerud AS, Dodds RH, Hampton RW, Dawicke DS. Three-dimensional modeling of ductile crack growth in thin sheet metals: computational aspects and validation. Engng Fract Mech 1999;63:347-74.

[33] James MA, Newman JC. The effect of crack tunneling on crack growth: experiments and CTOA analyses. Engng Fract Mech 2003;70:457-68.

[34] Faleskog J, Zaremba K, Nilsson F, Öberg H. An investigation of two- and three-dimensional elasto-plastic crack growth experiments. In: Proceedings of the Conference of European Symposium on Elastic-Plastic Fracture Mechanics: Defect Assessment in Components-Fundamentals and Applications, Freiburg, Germany, Mechanical Engineering Publications Ltd, London, 1991.

[35] Dawicke DS, Newman JC. Residual strength predictions for multiple-site damage using a three-dimensional finite-element analysis and a CTOA criterion. In: Sheppard SD, editor. ASTM STP 1332. American Society for Materials and Testing; 1999. p. 815-29.

[36] Joyce JA, Link RE. Fracture behavior of surface crack tension specimens in the ductile-brittle transition region. In: Sheppard SD, editor. Fatigue and fracture mechanics. ASTM STP 1332, vol. 29. West Consohocken, PA: The American Society for Testing and Materials; 1999.

[37] Michaud VJ. Liquid-state processing. In: Needleman A, editor. Fundamentals of metal matrix composites. ButterworthsHeinmann; 1993. p. 3-22.

[38] Mortensen A, Michaud VJ, Flemings MC. Pressure-infiltration processing of reinforced aluminum. JOM 1993;45(1):36-43.

[39] Mortensen A. Melt infiltration of metal matrix composites. In: Clyne TW, editor. Comprehensive composite materials. Metal matrix composites, vol. 3. Amsterdam: Elsevier; 2000. p. 521-54.

[40] Garcia-Cordovilla C, Louis E, Narciso J. Pressure infiltration of packed ceramic particulates by liquid metals. Acta Mater 1999;47(18):4461-79.

[41] SanMarchi C, Kouzeli M, Miserez A, Moser B, Rossoll A, Weber L, et al. Gas-pressure metal infiltration (invited paper). In: Proceedings of the Conference of ICETS 2000-Session 3: Advanced Materials Conference, Beijing, China, New World Press, 2000.

[42] Kouzeli M, Weber L, SanMarchi C, Mortensen A. Influence of damage on the tensile behaviour of pure aluminium reinforced with $>40$ vol. $\%$ alumina particles. Acta Mater 2001;49:3699-709.

[43] ASTM E-1737-96. Standard test method for $J$-integral characterization of fracture toughness, ASTM annual book of standards. Philadelphia: American Society for Testing and Materials, 1996.

[44] Measurements Groups I, Photoelastic Division. Strain measurement with the 030-Series Reflection Polariscope. Instruction manual, Raleigh, NC, USA, 1992.

[45] Kouzeli M, Mortensen A. Size dependent strengthening in particle reinforced aluminium. Acta Mater 2002;50:39-51.

[46] Kouzeli M. Tensile behaviour of aluminium reinforced with ceramic particles, PhD thesis, Ecole Polytechnique Fédérale de Lausanne (EPFL), Lausanne, 2001.

[47] Hutchinson JW. Single behaviour at the end of a tensile crack in a hardening material. J Mech Phys Solids 1968;16:13-31.

[48] Rice JR, Rosengren GF. Plane strain deformation near a crack tip in a power law hardening materials. J Mech Phys Solids $1968 ; 16: 1-12$.

[49] Brocks W, Klingbeil D, Olschewski J. Lösung der HRR-Feld Gleichungen der elastisch-plastischen Bruchmechanik, Forschungbericht 175, Bundesanstalt für Materialforschung und Prüfung (BAM), Berlin; 1990.

[50] ABAQUS Standard User's Manual. 5.8 ed., Hibbit, Karlsson \& Sorensen, Inc., Pawtucket, RI, USA, 1998.

[51] Brocks W, Scheider I. Reliable $J$-values. Numerical aspects of the path-dependence of the $J$-integral in incremental plasticity. MP Mater 2003;45:264-75.

[52] Anderson TL. Fracture mechanics. 2nd ed. CRC Press; 1995.

[53] Hutchinson JW, Paris PC. Stability analysis of $J$-controlled crack growth. In: Clarke GA, editor. Elastic-plastic fracture. ASTM STP 668. 1979. p. 37-64.

[54] Hutchinson JW. Fundamentals of the phenomenological theory of nonlinear fracture mechanics. J Appl Mech 1983;50:1042-51.

[55] Miserez A. Fracture and toughening of high volume fraction ceramic particle reinforced metals, PhD Thesis, Ecole Polytechnique Fédérale de Lausanne (EPFL), Lausanne, Switzerland, 2002. Available from: http://library.epfl.ch/theses/?display $=$ detail\&nr $=2703$.

[56] Prangnell PB, Downes T, Stobbs WM, Withers PJ. The deformation of discontinuously reinforced MMCs-I. The initial yielding behavior. Acta Metall Mater 1994;42(10):3425-36.

[57] Mortensen A. A review of the fracture toughness of particle reinforced aluminium alloys. In: Proceedings of the Conference on Fabrication of Particulates Reinforced Metal Composites, Montréal, Québec, Canada, ASM International, 1990. 